\title{
Self-Efficacy and the Sense of Coherence: Narrative Review and a Conceptual Synthesis
}

\author{
Paul Posadzki ${ }^{1, *}$ and Nel Glass ${ }^{2}$ \\ ${ }^{1}$ School of Medicine, Health Policy, and Practice, University of East Anglia, Norwich \\ NR4 7TJ, U.K.; ${ }^{2}$ ACU National/St. Vincent's \& Mercy Private Hospital, Easthill \\ House, 71 Victoria Parade, Fitzroy, VIC 3065, Australia \\ E-mail: P.Posadzki@uea.ac.uk; nel.glass@scu.edu.au
}

Received March 3, 2009; Revised August 27, 2009; Accepted August 27, 2009; Published September 14, 2009

\begin{abstract}
In this study, the authors develop an exploratory synthesis of two major health concepts: Antonovsky's sense of coherence and Bandura's beliefs in one's own efficacy. Reinterpretation of each study in the light of the other can lead to greater conceptual development and expand existing knowledge. The mutual themes are presented with an explanation of their contribution to broader conceptual discussions. The existence of some similarities between the two concepts is suggested. Researchers can obtain valuable and additional arguments through cross-fertilization of ideas across presented studies united by shared assumptions. Further research is recommended among various age groups and social backgrounds in order to verify the possible benefits of such theoretical development. Theoretical and practical implications of such a synthesis are presented.
\end{abstract}

KEYWORDS: sense of coherence, self-efficacy, narrative review, concept development

\section{INTRODUCTION}

Antonovsky's concept of the sense of coherence (SOC)[1] is a valuable scientific construct. Similarly, Bandura's theory of an individual's self-efficacy (SE)[2] can be regarded as a key concept applicable to health. Both are widely accepted due to their methodological importance and can be used in order to detect, predict, and change (improve) health status. Due to their relevance and appropriateness in explaining and describing individuals' states of health, both concepts have been given broad attention in the past 30 years.

The review question asks whether generalized resistance resources (GRR) can be developed through SE or whether belief in one's own efficacy may be strengthened by high SOC. The aim of this study is to address this question via description and conceptual synthesis of SE and SOC. Such a compilation may refresh both approaches to human health and bring new insights into the well-being problematic. Patients, therapists, and teachers may also benefit from this fusion.

Evaluation of the SOC construct in the light of SE may be beneficial from the overall well-being perspective in the sense that the addition of SE to SOC may enhance individuals' health resources. Conversely, individuals may develop beliefs in their own capabilities due to increased SOC with and within the Universe. This article reviews similarities and differences between and across diverse studies concerning 
SOC and SE in a narrative manner, and suggests some possible benefits of this fusion. The aim of the paper is to generate a conceptual synthesis of SOC and SE. The main areas of convergence are suggested.

\section{SELF-EFFICACY THEORY}

The concept of one's own efficacy that enables an individual to symbolize, learn from others, or plan alternative strategies is based on Bandura's Social Cognitive Theory[2] and cooperates with goal-aiming notion and one's expectations. It is suggested that this concept regulates an individual's motivation, behavior, and mood[3].

SE refers to people's beliefs about their capability to exercise control over the events affecting their lives. SE can also be thought of as the ability to organize and execute the courses of action required to manage prospective situations[3,4,5]. SE beliefs are concerned with judgment about what one can do with whatever skills one possesses[6] and has a complex effect on task performance. Results indicate that positive task experiences elicit a linear increase in SE[7].

Bandura[2] created a concept of self-reflection. This capability is thought to be an insight or selfawareness that is essential for producing enduring behavioral change([2], p.4). This reflection is thought to be a unique human capability that enables individuals to control their thoughts, feelings, and actions, and therefore might be particularly useful in various, e.g., stressful, life events.

It is also worth disseminating that education is an effective variable in improving an individual's SE[8]. Leganger and Kraf[9] state that the higher a person's educational status, the higher his/her SE. Schwarzer and Renner[10] present interesting findings concerning fluctuations of SE during the life span, which suggest that it may grow with age. In terms of gender difference, some authors claim that men report higher levels of SE than women[11]. Other authors suggest that SE differs with racial background[12]. Some researchers suggest that higher SE is strongly associated with higher income[13].

\section{SELF-EFFICACY AND HEALTH}

Giles et al.[14] argue that SE is a key construct in the area of health psychology. Numerous studies verify this statement. A few of these are presented below.

\section{Self-Efficacy and Health Behaviors}

Bandura[3] states that the Theory of Self-Efficacy is a real determinant of an individual's health behaviors and should be mentioned due to its importance. SE may be used as a predictor of health behaviors, such as exercise performance[15,16], cardiorespiratory fitness, weight loss[17], alcohol consumption[18], and oral health[19]. These results support the conceptual and empirical superiority of SE as a predictor of health behaviors and intentions[20].

Some research suggests that SE is important in the initiation and maintenance of a variety of physical activity programs[21,22,23], and a promising and positive indicator presaging sustainability and change in health behaviors[24]. It can be regarded as a closed circle because, conversely, greater physical activity may improve an individual's SE[21].

\section{Self-Efficacy and Mental Health}

Some studies indicate that a belief in SE enables individuals to cope with stress[25]. Others suggest that it is a powerful and modifiable determinant of depressive symptoms that can lead to mental well-being[26]. Sacco et al.[27] support this effect since they found that the effects of poor adherence to antidepressive 
drugs are mediated by lower SE perceptions. Conversely, greater SE is associated with higher perceptions of health[28].

\section{Social Benefits of Self-Efficacy}

Perkins et al.[29] state that SE can significantly predict social activities. Bandura et al.[5] appear to support this statement, as they have investigated the role of SE as a moderator of affective reactions of psychosocial functioning. Their research shows that SE significantly influences prosocial behaviors via empathy. Furthermore, higher perceived SE scores were associated with increased communication and partnership[30].

Self-presentation of one's own SE via positive health practices can strengthen self-esteem and selfappraisal, and therefore influence health behaviors[31].

\section{Self-Efficacy in Health Promotion and Disease Prevention}

Mosher et al.[32] presented findings that support the use of strategies to increase SE in health promotion interventions for cancer survivors. In terms of sexually transmitted diseases, SE might be effective in order to promote consistent condom use[33]. SE beliefs may facilitate disease prevention and therefore can be regarded as a positive medicine[34].

\section{Predictive and Prognostic Value of Self-Efficacy}

SE is correlated with health expectations and can be considered as a valid predictor of an individual's health practices[10]. Additionally, it has been suggested that SE can be seen as a useful, prognostic tool in the context of performing doctors' prescriptions[35].

\section{THE CONCEPT OF SENSE OF COHERENCE AS A PART OF GENERALIZED RESISTANCE RESOURCES}

Based on the Second Thermodynamics Law (all living organisms can be characterized by the drive to entropy), Antonovsky[1] created the notion of Salutogenesis. This model of health assumes that peoples' health can be situated at some place on the continuous "ease-disease" scale, and is thought to be in opposition to pathogenesis: health as a primordial state.

Aaron Antonovsky created the concept of GRR[1]. GRR are defined as each person's, environment's, or group's characteristics that facilitate effective coping with stress (p. 100). GRR include physical, biochemical (resistance), material, cognitive (knowledge, intellect, personality), and emotional factors associated with values, attitudes, and interpersonal relationships, as well as macrosociocultural qualities of individuals that enable them to avoid or conquer various kinds of stressors efficiently[36]. An individual's level of GRR determines how he/she perceives the world that is being expressed via SOC. According to Antonovsky, SOC is created by a few attitudes that form a kind of a "behavioral immunology" that leads to health[37]. SOC as part of GRR can be defined as a global orientation that creates dynamic and persistent beliefs, and that stimuli from the outside and inside worlds have a logical structure that can be predicted and explained. Individuals' available resources enable them to challenge these stimuli. Challenges are worth engaging and overcoming them may strengthen one's health. Antonovsky claims that the senses of comprehensibility, of manageability, and of meaningfulness are core components of SOC[1]. Comprehensibility (C) is regarded as the belief that incoming stimuli are coherent and make cognitive sense to the individual. Additionally, comprehensibility means that in 
relation to the future, these incentives will have logic and will be predictable. An individual may perceive manageability (Ma) as resources that he/she is able to use in order to challenge unexpected demands[36]. According to Antonovsky, meaningfulness (Me) is the crucial, motivation-emotional element of SOC. Persons with a high level of this SOC component feel that life makes emotional sense; it is worth engaging and investing energy, devotion, and commitment to. The challenges that sometimes occur are worth confronting and are therefore desired (p. 18). It should be added that Klepp et al.[38] measured within SOC model correlations and proved that $\mathrm{Ma}, \mathrm{C}$, and Me were found to be very highly and, in the case of sense of manageability and sense of comprehensibility, even perfectly correlated.

\section{THE SENSE OF COHERENCE AND HEALTH}

Antonovsky's research results indicate a significant correlation between a high level of SOC and overall health[37]. It has been suggested that the SOC is a key construct in the area of health psychology[36]. Recently researchers throughout the world have supported this declaration. Several research results are presented below.

\section{Sense of Coherence and Health Behaviors}

SOC is thought to be an individual's characteristics related to a positive life orientation leading to effective coping strategies[39]. Antonovsky's research shows statistically significant correlations between strong SOC and health behaviors[40]. The results of other studies provide similar conclusions[41,42, $43,44,45,46,47,48,49,50,51,52,53]$.

\section{Sense of Coherence and Mental Health}

Shiber et al.[54] have shown that perception of SOC can ease psychological disorders and reduce the risk of serious disability. Nevertheless, some inconsistencies exist in the literature concerning SOC and its relationship to anxiety and depressive symptoms[55]. These were confirmed when the SOC and coping responses did not mediate the relationship between perceived stress and post-traumatic stress[56,57]. However, other findings show that SOC offers most protective benefits to individuals exposed to symptoms of post-traumatic stress disorder[58]. It has also been shown that a strong SOC alleviates the development of distress[59,60]. Siglen et al.[61] state that SOC is significantly associated with depression; i.e., the stronger the SOC, the lower the levels of depression[62,63,64,65,66] and anxiety[65,67]. It has also been shown that the higher the SOC, the better the mental health of the respondent[68,69]. In addition, a highly significant correlation between psychological health and SOC was found[70,71]. Some findings also suggest that improving SOC in people with mental health problems might provide important opportunities for improving their satisfaction with life [72].

\section{Social Dimensions of Sense of Coherence}

Analyses by Marsh et al.[73] reveal that social support is a strong predictor of SOC. Similarly, social support has been found to be an important cornerstone in the restoration of a person's SOC[74]. The results also suggest that SOC is a potential marker of an individual's social adaptive capacities[75]. Conversely, maladaptive and antisocial behaviors correlate with poor SOC[76]. 


\section{Sense of Coherence in Health Promotion and Disease Prevention}

It has been suggested that SOC may support a design of future health promotion programs[57,68,77]. Moreover, Simonsson et al.[78] suggested the preventive value of SOC as a resource that strengthens resilience and develops a positive state of health.

\section{Predictive and Prognostic Value of Sense of Coherence}

Longitudinal studies have indicated a predictive value of SOC in terms of health and good quality of life (QOL)[68,79,80,81]. It has also been suggested that health-related QOL[82] and mortality[75] can be predicted using SOC. In addition, individuals with increased QOL have reported higher SOC scores[83]. Bergstein et al.[66] suggested a possible use of SOC as a prognostic tool.

\section{A CONCEPTUAL SYNTHESIS}

The main areas of convergence, theoretical and practical implications, and unaddressed questions are presented below.

\section{The Main Areas of Convergence}

From the health sciences perspective, it can be considered that both theories share similar underlying principles, i.e., their conceptual framework looks similar. $\mathrm{C}$, Me, and Ma may have their equivalents in Bandura's beliefs regarding sense of control over thoughts, feelings, and actions, respectively. Bandura's perception of one's own SE is thought to be a self-regulatory system that influences an individual's thoughts, feelings, and actions. Analogically, Antonovsky's sense of comprehensibility may be equivalent to the cognitive aspect of self-reflection; Antonovsky's sense of manageability may match the behavioral component of Bandura's concept; and finally, Antonovsky's sense of meaningfulness may well correspond to the emotional component of SE. To be more precise, the person's cognitive structures that they can reflect on efficiently are responsible for their vision of the world as coherent, sensible, and rational. Certainly, an individual will carry out appropriate actions and behaviors in order to manage environmental demands. Furthermore, he/she will be able to make sense of stressful life events and this can make a particular individual more "emotionally resistant".

The most explicit common feature of both approaches is that people who have strong beliefs in their capabilities approach difficult tasks as challenges to be mastered and worth confronting, and invest energy in them rather than see them as threats to be avoided[1,3].

1. Both concepts have therapeutic, diagnostic, and predictive value, and both can be used for health promotion and disease prevention.

2. Both can be applied to various dimensions of human health, i.e., psychological, physical, and social.

3. Both SE and SOC can enhance and develop an individual's health, well-being, and QOL.

4. As SOC and SE naturally fluctuate over the human life span, the ongoing development and strengthening of both increases health resources and promotes longevity.

5. Both can be "used" as health mediators and moderators.

6. Both SOC and SE may be developed due to such conceptual synthesis. 


\section{Theoretical Implications of Such a Combination}

Bandura ([2], pp. 4-5) writes that the value of a theory is ultimately judged by the power of the procedures it generates to effect psychological change. Moreover, effective theories must demonstrate predictive power.

Psychological changes might be achieved in the sense that SE beliefs, when added into SOC, may strengthen an individual's resources and coping strategies simultaneously. On the other hand, SOC, when incorporated into the SE concept, might develop beliefs in one's own efficacy. Moreover, people with a high SOC might be regarded as more likely to engage in self-reflection concerning their own health. Conversely, individuals with a high level of self-reflection may be more likely to explore their own relationship with the external world.

A combination of SOC and SE may have predictive power in the sense that efficacy beliefs might successfully enhance comprehension of an individual's current and future situation, and his/her ability to give meaning to various impulses bombarding the mind (emotional, cognitive) and to manage them. Furthermore, in terms of SOC's internal consistency, it may be assumed that a higher sense of comprehensibility may interact with and enhance cognitive and self-regulatory processes. The greater his/her sense of manageability or meaningfulness, the more likely an individual is to engage in courses of action required to manage prospective situations. Thoughts can interfere with comprehensibility, feelings with meaningfulness, and actions with manageability. But also within the combined model, interrelations may be observed between thoughts, feelings, and Me, Ma, and $\mathrm{C}$. Manageability may influence the sense of control over thoughts and feelings. Belief in meaningfulness can increase the sense of control over emotions. Analogically, such circumstances may be replicated with regard to manageability and comprehensibility. The conclusion might be as follows: belief in one's own control over thoughts, feelings, and actions may improve $\mathrm{Ma}, \mathrm{Me}$, and $\mathrm{C}$.

Certainly, a high level of SE can give an individual the ability to classify the structure of the impulses approaching one's life more effectively. Moreover, increased SE can be used as a strategy for coping with stress. Conversely, categorized impulses and a strong SOC may, in turn, enhance perceived SE. Selfreflection regarding one's own emotional resistance may be useful when some behavioral interventions are required.

\section{Practical Implications and Guidelines}

Policy makers who create a wider health strategy might use a health model based on combined concepts of SE and SOC[84]. For instance, both could be applicable to learning processes in institutions such as schools and academies. This would enable young people to acquire knowledge and skills useful for coping with stress, strengthen their health resources, and enhance their well-being. Both SOC and SE could be part of the explicit curriculum taught continuously at the early stages of ontogenesis, and would give them tools for managing challenging life events.

SE and SOC as a consistent collective may be used in clinical practice, solely or in combination with other therapeutic modalities such Cognitive Behavioral Therapy, Gestalt Therapy, or humanistic approaches, such as patient-centered therapy for patients' best benefits. Moreover, rehabilitation specialists and their cardiology, orthopedic, neurology, pulmonology, and pediatric patients could also benefit from such an incorporation. Exercising control over thoughts, feelings, and actions may be more feasible when one believes in the world's coherence and the logic of one's own existence.

The main practical implications of the combination of both approaches can also be analyzed from a coping strategy perspective. According to Antonovsky, if SOC as behavioral immunology can be mediated, SE is thought to be a key mediator in terms of planning the resources to be used. This would develop the individual's GRR and improve his/her self-confidence and general state of health. SE can be regarded as a moderator of GRR that facilitates an individual's satisfaction with life. Surely, engagement in the process of giving a meaning into an individual's life events should include emotional SE. This 
would allow development of the individual's emotional resistance or flexibility, and consequently promote social interaction via prosocial behavior, such as altruism and/or empathy.

From the health promotion perspective, SE added to SOC can be used in the process of encouraging people to prevent disease, strengthening their health potential or reservoir, and for persistent selfdevelopment[84].

\section{Questions that Remain Unanswered}

1. Does the nature of beliefs need to explored in greater depth since both models are based on them?

2. Would it be scientifically interesting to investigate mutual correlations between sense of manageability and the behavioral component of SE, or sense of comprehensibility and the cognitive "part" of SE?

3. Can pressure toward entropy be minimized to some extent through motivation towards selforganization (reversed entropy) and conscious control over one's own thoughts, feelings, and emotions?

4. Can an individual's health be shifted nearer to the "ease" end of the ease/disease continuum?

5. Can high SE strengthen physical, emotional, cognitive, spiritual, and material resources?

6. How can these two related concepts be used in conjunction with one another?

7. What is the synergistic effect of, for example, high SE and high SOC over and above their main effects? And who tends to experience more under what conditions?

\section{CRITICAL REFLECTIONS}

It appears that Antonovsky's construct does not have strong predictive power in terms of health behaviors. There is also a lack of motivational variables in Antonovsky's model. On the other hand, Bandura's concept of SE does not include a "philosophical component" regarding human existence[2] and SOC, therefore, could be incorporated into SE in order to increase its completeness.

Future research to investigate the correlations between SOC and SE among various age groups with different educational status and social backgrounds should be performed to measure the validity, reliability, and specificity of the new construct.

Of course, such conceptual synthesis may be questioned, but it seems that a unified theory in the area of health psychology/sciences would be a useful adjunct to current and future research.

\section{REFERENCES}

1. Antonovsky, A. (1979) Health, Stress and Coping. Jossey-Bass, San Francisco.

2. Bandura, A. (1977) Self-efficacy: toward a unifying theory of behavioural change. Psychol. Rev. 84, 191-215.

3. Bandura, A. (1997) Self-Efficacy. The Exercise of Control. W.H. Freeman, New York.

4. Bandura, A. (1989) Human agency in social cognitive theory. Am. Psychol. 44(9), 1175-1184.

5. Bandura, A., Caprara, G.V., Barbaranelli, C., Gerbino, M., and Pastorelli, C. (2003) Role of affective self-regulatory efficacy in diverse spheres of psychosocial functioning. Child Dev. 74(3), 769-782.

6. Bandura, A. (1986) Social Foundations of Thought and Action: A Social Cognitive Theory. Prentice Hall, Englewood Cliffs, NJ.

7. Chiou, W.B. and Wan, C.S. (2007) The dynamic change of self-efficacy in information searching on the Internet: influence of valence of experience and prior self-efficacy. J. Psychol. 141(6), 589-603.

8. Ju, K. and So, H. (2008) Effects of the nutrition education program on self-efficacy, diet behavior pattern and cardiovascular risk factors for the patients with cardiovascular disease. Taehan Kanho Hakhoe Chi 38(1), 64-73. [Korean]

9. Leganger, A. and Kraft, P. (2003) Control constructs: do they mediate the relation between educational attainment and health behaviour? J. Health Psychol. 8(3), 361-372. 
10. Schwarzer, R. and Renner, B. (2000) Social-cognitive predictors of health behavior: action self-efficacy and coping self-efficacy. Health Psychol. 19(5), 487-495.

11. Presnell, K., Pells, J., Stout, A., and Musante, G. (2008) Sex differences in the relation of weight loss self-efficacy, binge eating, and depressive symptoms to weight loss success in a residential obesity treatment program. Eat. Behav. 9(2), 170-180.

12. Chang, M.W., Brown, R.L., Baumann, L.J., and Nitzke, S.A. (2008) Self-efficacy and dietary fat reduction behaviors in obese African-American and white mothers. Obesity (Silver Spring) 16(5), 992-1001.

13. Siahpush, M., Borland, R., Yong, H.H., Kin, F., and Sirirassamee, B. (2008) Socio-economic variations in tobacco consumption, intention to quit and self-efficacy to quit among male smokers in Thailand and Malaysia: results from the International Tobacco Control-South-East Asia (ITC-SEA) survey. Addiction 103(3), 502-508.

14. Giles, M., McClenahan, C., Cairns, E., and Mallet, J. (2004) An application of the Theory of Planned Behaviour to blood donation: the importance of self-efficacy. Health Educ. Res. 19(4), 380-391.

15. Takase, K. (2007) Prospective study of the relation between exercise performance for health promotion, selfefficacy, and outcome expectation of elderly people. Nippon Ronen Igakkai Zasshi 44(1), 107-116. [Japanese]

16. Hepler, T.J. and Chase, M.A. (2008) Relationship between decision-making self-efficacy, task self-efficacy, and the performance of a sport skill. J. Sports Sci. 26(6), 603-610.

17. Warziski, M.T., Sereika, S.M., Styn, M.A., Music, E., and Burke, L.E. (2008) Changes in self-efficacy and dietary adherence: the impact on weight loss in the PREFER study. J. Behav. Med. 31(1), 81-92.

18. Oei, T.P., Hasking, P., and Phillips, L. (2007) A comparison of general self-efficacy and drinking refusal selfefficacy in predicting drinking behavior. Am. J. Drug Alcohol Abuse 33(6), 833-841.

19. Basak, C.A., Nilufer, K., and Murtomaa, H. (2005) Self-efficacy perspective on oral health among Turkish preadolescents. Oral Health Prev. Dent. 3(4), 209-215.

20. Rodgers, W.M. and Murray, T.C. (2007) Distinguishing among perceived control, perceived difficulty, and selfefficacy as determinants of intentions and behaviours. Br. J. Soc. Psychol. 47(Pt 4), 607-630.

21. Motl, R.W. and Snook, E.M. (2008) Physical activity, self-efficacy, and quality of life in multiple sclerosis. Ann. Behav. Med. 35(1), 111-115.

Morris, K.S., McAuley, E., and Motl, R.W. (2008) Neighborhood satisfaction, functional limitations, and selfefficacy influences on physical activity in older women. Int. J. Behav. Nutr. Phys. Act. 5, 13.

23. Snook, E.M. and Motl, R.W. (2008) Physical activity behaviors in individuals with multiple sclerosis: roles of overall and specific symptoms, and self-efficacy. J. Pain Symptom Manage. 36(1), 46-53.

24. Zalewska-Puchała, J., Majda, A., Gałuszka, A., and Kolonko, J. (2007) Health behaviour of students versus a sense of self-efficacy. Adv. Med. Sci. 52(Suppl 1), 73-77.

25. Bandura, A., Cioffi, D., Taylor, C.B., and Brouillard, M.E. (1988) Perceived self-efficacy in coping with cognitive stressors and opioid activation. J. Pers. Soc. Psychol. 55(3), 479-488.

26. Weng, L.C., Dai, Y.T., Wang, Y.W., Huang, H.L., and Chiang, Y.J. (2008) Effects of self-efficacy, self-care behaviours on depressive symptom of Taiwanese kidney transplant recipients. J. Clin. Nurs. 17(13), 1786-1794.

27. Sacco, W.P., Wells, K.J., Friedman, A., Matthew, R., Perez, S., and Vaughan, C.A. (2007) Adherence, body mass index, and depression in adults with type 2 diabetes: the mediational role of diabetes symptoms and self-efficacy. Health Psychol. 26(6), 693-700.

28. Reece, S.M. and Harkless, G.E. (2006) Perimenopausal health self-efficacy among Hispanic Caribbean and nonHispanic white women. Health Care Women Int. 27(3), 223-237.

29. Perkins, J.M., Multhaup, K.S., Perkins, H.W., and Barton, C. (2008) Self-efficacy and participation in physical and social activity among older adults in Spain and the United States. Gerontologist 48(1), 51-58.

30. Curtin, R.B., Walters, B.A., Schatell, D., Pennell, P., Wise, M., and Klicko, K. (2008) Self-efficacy and selfmanagement behaviors in patients with chronic kidney disease. Adv. Chronic Kidney Dis. 15(2), 191-205.

31. Pajares, F. (1996) Self-efficacy beliefs and mathematical problem-solving of gifted students. Contemp. Educ. Psychol. 21(4), 325-344.

32. Mosher, C.E., Fuemmeler, B.F., Sloane, R., Kraus, W.E., Lobach, D.F., Snyder, D.C., and Demark-Wahnefried, W. (2008) Change in self-efficacy partially mediates the effects of the FRESH START intervention on cancer survivors' dietary outcomes. Psychooncology 17(10), 1014-1023.

33. Kaneko, N. (2007) Association between condom use and perceived barriers to and self-efficacy of safe sex among young women in Japan. Nurs. Health Sci. 9(4), 284-289.

34. Robinson, J.K., Stapleton, J., and Turrisi, R. (2008) Relationship and partner moderator variables increase selfefficacy of performing skin self-examination. J. Am. Acad. Dermatol. 58(5), 755-762.

35. Risser, J., Jacobson, T.A., and Kripalani, S. (2007) Development and psychometric evaluation of the Self-efficacy for Appropriate Medication Use Scale (SEAMS) in low-literacy patients with chronic disease. J. Nurs. Meas. 15(3), 203-219.

36. Antonovsky, A (1987) Unraveling the Mystery of Health. How People Manage Stress and Stay Well. Jossey-Bass, London.

37. Antonovsky, A. (1997) Self efficacy as a health determinant. In Psychologia zdrowia (Health Psychology). HeszenNiejodek, I. and Sek, H., Eds. Polish Science Press, Warsaw. 
38. Klepp, O.M., Mastekaasa, A., Sørensen, T., Sandanger, I., and Kleiner, R. (2007) Structure analysis of Antonovsky's sense of coherence from an epidemiological mental health survey with a brief nine-item sense of coherence scale. Int. J. Methods Psychiatr. Res. 16(1), 11-22.

39. Kouvonen, A.M., Väänänen, A., Woods, S.A., Heponiemi, T., Koskinen, A., and Toppinen-Tanner, S. (2008) Sense of coherence and diabetes: a prospective occupational cohort study. BMC Public Health 8, 46.

40. Antonovsky, A. (1993) The structure and properties of the sense of coherence scale. Soc. Sci. Med. 36(6), 725-733.

41. Nyamathi, A.M. (1991) Relationship of resources to emotional distress, somatic complaints, and high-risk behaviors in drug recovery and homeless minority women. Res. Nurs. Health 14(4), 269-277.

42. Ogawa, Y., Nakamura, H., Nagase, H., Ogino, K., Ooshita, Y., and Tsukahara, S. (2001) Structural analysis for psychosocial factors including health locus of control (HLC) and sense of coherence (SOC) associated with lifestyle-related diseases. Nippon Eiseigaku Zasshi 55(4), 597-606. [Japanese]

43. Kamwendo, K., Hansson, M., and Hjerpe, I. (1998) Relationships between adherence, sense of coherence, and knowledge in cardiac rehabilitation. Rehabil. Nurs. 23(5), 240-245, 251.

44. Abel, T., Walter, E., Niemann, S., and Weitkunat, R. (1999) The Berne-Munich Lifestyle Panel. Background and baseline results from a longitudinal health lifestyle survey. Soz. Praventivmed. 44(3), 91-106.

45. Freire, M.C., Sheiham, A., and Hardy, R. (2001) Adolescents' sense of coherence, oral health status, and oral healthrelated behaviours. Community Dent. Oral Epidemiol. 29(3), 204-212.

46. Luszczynska, A. (2002) Sense of coherence and smoking in a sample of abused women. Psychol. Rep. 90(3 Pt 2), 1123-1128.

47. Cohen, M. and Kanter, Y. (2004) Relation between sense of coherence and glycemic control in type 1 and type 2 diabetes. Behav. Med. 29(4), 175-183.

48. Savolainen, J., Knuuttila, M., Suominen-Taipale, L., Martelin, T., Nordblad, A., Niskanen, M., and Uutela, A. (2004) A strong sense of coherence promotes regular dental attendance in adults. Community Dent. Health 21(4), 271-276.

49. Savolainen, J., Suominen-Taipale, A.L., Hausen, H., Harju, P., Uutela, A., Martelin, T., and Knuuttila, M. (2005) Sense of coherence as a determinant of the oral health-related quality of life: a national study in Finnish adults. Eur. J. Oral Sci. 113(2), 121-127.

50. Savolainen, J., Suominen-Taipale, A.L., Uutela, A.K., Martelin, T.P., Niskanen, M.C., and Knuuttila, M.L. (2005) Sense of coherence as a determinant of toothbrushing frequency and level of oral hygiene. J. Periodontol. 76(6), 1006-1012.

51. Honkinen, P.L., Suominen, S.B., Välimaa, R.S., Helenius, H.Y., and Rautava, P.T. (2005) Factors associated with perceived health among 12-year-old school children. Relevance of physical exercise and sense of coherence. Scand. J. Public Health 33(1), 35-41.

52. Myrin, B. and Lagerström, M. (2006) Health behaviour and sense of coherence among pupils aged 14-15. Scand. J. Caring Sci. 20(3), 339-346.

53. Sollerhed, A.C., Ejlertssonb, G., and Apitzsch, E. (2005) Predictors of strong sense of coherence and positive attitudes to physical education in adolescents. Scand. J. Public Health 33(5), 334-342.

54. Shiber, A., Maoz, B., Antonovsky, A., and Antonovsky, H. (1990) Detection of emotional problems in the primary care clinic. Fam. Pract. 7(3), 195-200.

55. Konttinen, H., Haukkala, A., and Uutela, A. (2008) Comparing sense of coherence, depressive symptoms and anxiety, and their relationships with health in a population-based study. Soc. Sci. Med. 66(12), 2401-2412.

56. Arévalo, S., Prado, G., and Amaro, H. (2008) Spirituality, sense of coherence, and coping responses in women receiving treatment for alcohol and drug addiction. Eval. Program Plann. 31(1), 113-123.

57. Ying, Y.W., Lee, P.A., and Tsai, J.L. (2007) Predictors of depressive symptoms in Chinese American college students: parent and peer attachment, college challenges and sense of coherence. Am. J. Orthopsychiatry 77(2), 316323.

58. Nielsen, M.B., Matthiesen, S.B., and Einarsen, S. (2008) Sense of coherence as a protective mechanism among targets of workplace bullying. J. Occup. Health Psychol. 13(2), 128-136.

59. Delgado, C. (2007) Sense of coherence, spirituality, stress and quality of life in chronic illness. J. Nurs. Scholarsh. 39(3), 229-234.

60. Gustavsson-Lilius, M., Julkunen, J., Keskivaara, P., and Hietanen, P. (2007) Sense of coherence and distress in cancer patients and their partners. Psychooncology 16(12), 1100-1110.

61. Siglen, E., Bjorvatn, C., Engebretsen, L.F., Berglund, G., and Natvig, G.K. (2007) The influence of cancer-related distress and sense of coherence on anxiety and depression in patients with hereditary cancer: a study of patients' sense of coherence 6 months after genetic counseling. J. Genet. Couns. 16(5), 607-615.

62. Roth, G. and Ekblad, S. (2006) A longitudinal perspective on depression and sense of coherence in a sample of mass-evacuated adults from Kosovo. J. Nerv. Ment. Dis. 194(5), 378-381.

63. Chumbler, N.R., Rittman, M.R., and Wu, S.S. (2008) Associations in sense of coherence and depression in caregivers of stroke survivors across 2 years. J. Behav. Health Serv. Res. 35(2), 226-234.

64. Gottberg, K., Einarsson, U., Fredrikson, S., von Koch, L., and Holmqvist, L.W. (2007) A population-based study of depressive symptoms in multiple sclerosis in Stockholm county: association with functioning and sense of coherence. J. Neurol. Neurosurg. Psychiatry 78(1), 60-65. 
65. Lam, B.T. (2007) Impact of perceived racial discrimination and collective self-esteem on psychological distress among Vietnamese-American college students: sense of coherence as mediator. Am. J. Orthopsychiatry 77(3), 370376.

66. Bergstein, M., Weizman, A., and Solomon, Z. (2008) Sense of coherence among delusional patients: prediction of remission and risk of relapse. Compr. Psychiatry 49(3), 288-296.

67. Langius, A., Björvell, H., and Antonovsky, A. (1992) The sense of coherence concept and its relation to personality traits in Swedish samples. Scand. J. Caring Sci. 6(3), 165-171.

68. Eriksson, M. and Lindström, B. (2006) Antonovsky's sense of coherence scale and the relation with health: a systematic review. J. Epidemiol. Community Health 60(5), 376-381.

69. Eriksson, M., Lindström, B., and Lilja, J. (2007) A sense of coherence and health. Salutogenesis in a societal context: Aland, a special case? J. Epidemiol. Community Health 61(8), 684-688.

70. Flensborg-Madsen, T., Ventegodt, S., and Merrick, J. (2006) Sense of coherence and physical health. The emotional sense of coherence (SOC-E) was found to be the best-known predictor of physical health. TheScientificWorldJOURNAL 6, 2147-2157.

71. Volanen, S.M., Suominen, S., Lahelma, E., Koskenvuo, M., and Silventoinen, K. (2007) Negative life events and stability of sense of coherence: a five-year follow-up study of Finnish women and men. Scand. J. Psychol. 48(5), 433-441.

72. Langeland, E., Wahl, A.K., Kristoffersen, K., Nortvedt, M.W., and Hanestad, B.R. (2007) Sense of coherence predicts change in life satisfaction among home-living residents in the community with mental health problems: a 1year follow-up study. Qual. Life Res. 16(6), 939-946.

73. Marsh, S.C., Clinkinbeard, S.S., Thomas, R.M., and Evans, W.P. (2007) Risk and protective factors predictive of sense of coherence during adolescence. J. Health Psychol. 12(2), 281-284.

74. Skärsäter, I., Langius, A., Agren, H., Häggström, L., and Dencker, K. (2005) Sense of coherence and social support in relation to recovery in first-episode patients with major depression: a one-year prospective study. Int, J, Ment, Health Nurs. 14(4), 258-264.

75. Surtees, P.G., Wainwright, N.W., and Khaw, KT. (2006) Resilience, misfortune, and mortality: evidence that sense of coherence is a marker of social stress adaptive capacity. J. Psychosom. Res. 61(2), 221-227.

76. Ristkari, T., Sourander, A., Ronning, J., and Helenius, H. (2006) Self-reported psychopathology, adaptive functioning and sense of coherence, and psychiatric diagnosis among young men-a population-based study. Soc. Psychiatry Psychiatr. Epidemiol. 41(7), 523-531.

77. Wainwright, N.W., Surtees, P.G., Welch, A.A., Luben, R.N., Khaw, K.T., and Bingham, S.A. (2007) Healthy lifestyle choices: could sense of coherence aid health promotion? J. Epidemiol. Community Health 61(10), 871-876.

78. Simonsson, B., Nilsson, K.W., Leppert, J., and Diwan, V.K. (2008) Psychosomatic complaints and sense of coherence among adolescents in a county in Sweden: a cross-sectional school survey. Biopsychosoc. Med. 2, 4.

79. Abu-Shakra, M., Keren, A., Livshitz, I., Delbar, V., Bolotin, A., Sukenik, S., and Kanat-Maymon, Y. (2006) Sense of coherence and its impact on quality of life of patients with systemic lupus erythematosus. Lupus 15(1), 32-37.

80. Eriksson, M. and Lindström, B. (2007) Antonovsky's sense of coherence scale and its relation with quality of life: a systematic review. J. Epidemiol. Community Health 61(11), 938-944.

81. Suresky, M.J., Zauszniewski, J.A., and Bekhet, A.K. (2008) Sense of coherence and quality of life in women family members of the seriously mentally ill. Issues Ment. Health Nurs. 29(3), 265-278.

82. Ekwall, A.K., Sivberg, B., and Hallberg, I.R. (2007) Older caregivers' coping strategies and sense of coherence in relation to quality of life. J. Adv. Nurs. 57(6), 584-596.

83. Borglin, G., Jakobsson, U., Edberg, A.K., and Hallberg, I.R. (2006) Older people in Sweden with various degrees of present quality of life: their health, social support, everyday activities and sense of coherence. Health Soc. Care Community 14(2), 136-146.

84. Silva, A.N., Mendonça, M.H., and Vettore, M.V. (2008) A salutogenic approach to oral health promotion. Cad. Saude Publica 24(Suppl 4), s521-530.

\section{This article should be cited as follows:}

Posadzki, P. and Glass, N. (2009) Self-efficacy and the sense of coherence: narrative review and a conceptual synthesis. TheScientificWorldJOURNAL: TSW Holistic Health \& Medicine 9, 924-933. DOI 10.1100/tsw.2009.107. 